WORLD VIEW

\title{
The prevalence and causes of visual impairment in Tehran: the Tehran Eye Study
}

\author{
A Fotouhi, H Hashemi, K Mohammad, K H Jalali
}

Br J Ophthalmol 2004;88:740-745. doi: 10.1136/bjo.2003.031153

Series editors: W V Good and S Ruit

See end of article for authors' affiliations

Correspondence to: A Fotouhi, MD, PhD, Epidemiology and Biostatistics Department School of Public Health, Tehran University of Medical Sciences, No 6, Babak Bahrami Street, Valiasr Avenue, 19686 55751, Tehran, Iran; afotouhi@sina.tums.ac.ir

Accepted for publication 3 November 2003

\begin{abstract}
Aims: To determine the prevalence and causes of visual impairment in Tehran, Iran, through a population based study.

Methods: In a population based, cross sectional study, 6497 Tehran citizens were sampled from 160 clusters using a stratified, random, cluster sampling strategy. The eligible people were enumerated through a door to door household survey in the selected clusters and were invited. All participants were transferred to a clinic for an extensive eye examination and interview. Visual impairment was determined using presenting and best corrected visual acuity (low vision: visual acuity of less than $6 / 18$ to $3 / 60$ in the better eye; blindness: visual acuity of less than $3 / 60$ in the better eye).

Results: Of those sampled, 4565 (70.3\%) people participated in the study. The age and sex standardised prevalences of visual impairment on the basis of best corrected and presenting visual acuity were $1.39 \%$ (95\% confidence interval $(\mathrm{Cl}), 1.07$ to 1.71$)$ and $2.52 \%(95 \% \mathrm{Cl}, 2.07$ to 2.97$)$, respectively. 15 people (0.28\%; $95 \% \mathrm{Cl}, 0.14$ to 0.42$)$ were blind with corrected vision while $22(0.39 \% ; 95 \% \mathrm{Cl}, 0.23$ to 0.56$)$ were blind with presenting vision. Using the corrected and presenting vision, the prevalence of low visual impairment was $1.11 \%(95 \% \mathrm{Cl}, 0.84$ to 1.39$)$ and $2.13 \%(95 \% \mathrm{Cl}, 1.71$ to 2.55$)$, respectively. The causes of visual impairment according to the best corrected vision were cataract $(36.0 \%)$, macular degeneration (20.0\%), and amblyopia (10.7\%). However, according to the presenting vision, uncorrected refractive errors were the most frequent primary cause $(33.6 \%)$ and cataract $(25.4 \%)$, macular degeneration $(12.7 \%)$, and amblyopia $(8.2 \%)$ were the other main causes of visual impairment in the study sample. The prevalence of visual impairment was associated with advancing age and lower education.

Conclusion: The results indicate that the burden of visual impairment is important and, although easily preventable, uncorrected refractive errors and cataract have a major role as causes of visual impairment in this population. Results also highlight the need for visual impairment prevention programmes, with emphasis on treatment of refractive errors and cataract.
\end{abstract}

$\mathrm{V}$ sual impairment is a global public health problem Worldwide, an estimated 45 million people are blind, and an additional 135 million are severely visually impaired. ${ }^{12}$ While the majority of blind people worldwide reside in the developing nations of Africa, Asia, and Latin America, close to three quarters of the world's blindness is either curable or preventable. ${ }^{3}$ So the control of the problem is a priority for these countries. There are several studies on the prevalence of visual impairment in the world ${ }^{4-35}$ and eastern Mediterranean countries. ${ }^{373132}$ On the other hand the epidemiology of visual impairment is complicated and encompasses a wide variety of factors and strategies and controlling the problem needs to be region specific, based on data in the community. Thus, providing appropriate data is one of the first steps in these communities, as it is in Iran. There are very few published studies about the status of the problem in the Iranian population. ${ }^{36}$ The national health survey in Iran provided some data on visual impairment. ${ }^{37}$ These data, based on self report visual assessment, had some limitations. Thus, the Tehran Eye Study (TES) was conducted in a representative sample of the Tehran population to determine the prevalence of visual impairment and its major causes in the population of Tehran city.

\section{MATERIALS AND METHODS}

The Tehran Eye Study is a population based cross sectional study. Detailed descriptions of the method of this study have been published previously $y^{38}$ and are summarised here.

\section{Study population}

In the 1996 national census, the population of Tehran city was 6.8 million. We estimate that the total population will be nearly 7.5 million in year 2002. The sampling strategy of the study followed a stratified cluster sampling procedure with proportional allocation within strata. The survey target population comprised non-institutionalised urban citizens of all ages, who resided in Tehran city in 2002. The stratification of the sample according to the 22 municipal districts of Tehran city is incorporated in the sampling process. An appropriate number of clusters was assigned to each of the 22 districts, proportional to the number of households. A total of 160 clusters were randomly selected based on block enumeration of the national census of 1996 by the Statistical Center of Iran. For each cluster, a team consisting of two interviewers (one man and one woman) approached the first household. They introduced themselves by their identification cards. Then they described the project to the members of the household who were present. At the end, all household members were invited for a complete eye examination at Noor Vision Correction Centre. They received an invitation card in which the date and time of the visit were stated. Enumeration was continued for 10 neighbouring households by proceeding systematically in a clockwise direction from the initial household within the cluster. The participants were transported to the clinic. Considering design effect and response rate, a total sample size of 5300 was calculated to estimate an expected prevalence of $2 \%$, with a precision of $0.5 \%$ and a confidence level of $95 \%$. 


\section{Examination process}

All participants in the Tehran Eye Study received thorough eye examinations. The examination protocol included uncorrected, best corrected and presenting visual acuity measurements; manifest, subjective and cycloplegic refraction; colour vision test; Goldmann applanation tonometry; lensometry; examination of the external eye, anterior segment, media, and fundus; and an interview about demographic characteristics, past history of eye diseases, eye trauma, diabetes mellitus, hypertension, and any ophthalmological care the participant received. The examiners were not masked to the covariates-age, education, or sex of the subjects.

Visual acuity was determined by using a Nidek chart projector (CP-670 20/10-20/400; Nidek Co, Gamagori, Japan) with tumbling E letters at a distance of 4 metres. The participants' visual acuity without correction was measured separately for each eye and presenting acuity was measured with the participants' habitual distance correction. Then visual acuity was tested with best spectacle correction. Visual acuity was recorded as the smallest line in which the patient could read the four letters correctly. If the person was unable to read the largest $\mathrm{E}$ letters in the chart (20/400 E letters) at 4 metres, then finger counting was done at 1 metre. The examiner stood 1 metre away in front of the participant and asked if the participant could see his/her hand. The examiner slowly waved his/her hand and asked the participant if he/ she could see what the hand was doing. If the participant was able to see the examiner's hand moving, "hand motion" was recorded on the examination form. If the participant could not see the examiner's hand, a penlight was held in front of the participant's eye and he/she was asked if he/she could tell when the light was on. If the participant could correctly identify when the light was on, "light perception" was recorded on the examination form. If the participant was unable to see the light, "no light perception" was recorded.

\section{Definitions}

The International Classification of Diseases 10th edition (ICD10) defines visual impairment as a visual acuity of less than $6 / 18(20 / 60,0.3)$ in the better eye with the best correction. ${ }^{39}$ Visual impairment has been categorised to blindness and low vision. A visual acuity of less than 3/60 $(20 / 400,0.05)$ in the better eye with the best correction has been considered blindness. Low vision has been defined as a best corrected visual acuity of less than $6 / 18(20 / 60,0.3)$ but not less than $3 / 60(20 / 400,0.05)$ in the better eye. We are also using presenting visual acuity to describe visual impairment within the study sample.

An ophthalmologist determined the cause of visual impairment. Using the best judgment, the ophthalmologist determined one cause for each eye as the principal cause in either eye. When multiple disorders were present, the ophthalmologist attempted to identify the disorder causing the greatest limitation of vision. If there were any other contributory causes, the ophthalmologist specified that as a second cause. In cases with different causes of visual reduction in a patient's two eyes, the diagnosis in the less affected eye was used..$^{22}$ When two causes appeared to have an equal contribution to visual impairment the primary cause was assigned to the one that was amenable to treatment to restore vision. Cataract was regarded as the main cause of severe low vision if the fundus was obscured by lens changes or if no evident fundus abnormalities were observed in eyes with significant cataract.

\section{Humanity and ethics}

The research and ethics committee of the Noor Vision Correction Centre and ethics committee of the National Research Centre for Medical Sciences approved the study. All subjects included in this study were informed about the project and the procedures in their native language before being enrolled. The participant's agreement for examination was obtained verbally.

\section{Quality assurance}

All observers (including enumerators, optometrists, and ophthalmologists) took part in a comprehensive training course, which had been developed for conducting the protocol. All observers received regular quality control visits from the project manager who checked their performance. In addition, interobserver comparison of visual acuity measurements between the optometrists was carried out in 578 eyes during the study, 30 of which had visual acuity less than $6 / 18$. With visual acuity categories defined as normal, low vision, and blind, there was agreement in 570 (98.6\%) of the 578 eyes $($ kappa $=0.85)$.

\section{Statistical methods}

The prevalence of visual impairment and the causes were calculated as percentages of the total study population and stratified by age and sex. In calculating standard errors and 95\% confidence interval (CI), the cluster sampling design was taken into account and adjusted for. ${ }^{40}$ The design effect for the main outcome was 1.22. Rates have been age and sex standardised to the 1996 Tehran population using data from the Iranian Statistics Centre by the direct method. Multiple logistic regression was used to investigate the association of visual impairment with age, sex, and education. Odds ratios (ORs) and 95\% confidence intervals were reported. The 95\% confidence intervals were calculated by assuming normal approximation of binomial distribution for rates with five or more outcome observations, and Poisson distribution for rates with fewer outcome observations. Age was grouped to under 20 years old, 20-39, 40-59, and 60 years old or more. Education was categorised as none for those with no formal schooling, primary for those with $1-5$ years of schooling, secondary for those with at least 7 years of schooling and before college, and college for those more than 12 years of schooling. All analyses were done using Stata statistical software, version 6.0 (Stata Corporation, TX, USA).

\section{RESULTS}

\section{Participants}

Between August and December 2002, of the 6497 eligible individuals in the sample, 4565 participants completed the interview and the ophthalmic examination (participation rate of $70.3 \%$ ). Table 1 displays demographic characteristics of participants compared with the Tehran population. ${ }^{41}$ The age and sex distribution of participants was different from the population of the city. People over 40 years of age were overrepresented in the sample. Male sex was under-represented in the sample in comparison to the city population. The mean age was 29.9 years in men and 30.2 years in women.

\section{Prevalence and causes of visual impairment}

Of the 4565 participants, 75 (1.64\%) and 134 (2.94\%) had visual impairment based on best corrected visual acuity and presenting visual acuity respectively. The age and sex specific prevalence rates of visual impairment (blindness and low vision) on the basis of best corrected visual acuity and presenting visual acuity are shown in tables 2 and 3. The prevalence rates are adjusted for age based on the age distribution of Tehran population in the Iranian 1996 population census. The difference between men and women in the distribution of both presenting and best corrected vision was not statistically significant. In both sexes the prevalence of visual impairment increases with advancing age. 
Table 1 Characteristics of participants compared with Tehran population

\begin{tabular}{|c|c|c|}
\hline \multirow[b]{2}{*}{ Characteristics } & \multirow{2}{*}{$\begin{array}{l}\text { Participants } \\
\text { No (\%) }\end{array}$} & \multirow{2}{*}{$\begin{array}{l}\text { Tehran population }{ }^{*} \\
\text { No (\%) }\end{array}$} \\
\hline & & \\
\hline \multicolumn{3}{|c|}{ Age groups (years) } \\
\hline & $557(12.20)$ & $1103539(16.60)$ \\
\hline $10-19$ & $1159(25.39)$ & $1629238(24.51)$ \\
\hline $20-29$ & $744(16.30)$ & 1222077 (18.39) \\
\hline $30-39$ & $671(14.70)$ & $1048618(15.78)$ \\
\hline $40-49$ & 631 (13.82) & $717701(10.80)$ \\
\hline $50-59$ & $417(9.14)$ & 431675 (6.49) \\
\hline $60-69$ & $223(4.88)$ & 304455 (4.58) \\
\hline $70+$ & $163(3.57)$ & $189772(2.85)$ \\
\hline \multicolumn{3}{|l|}{ Sex } \\
\hline Male & $1909(41.82)$ & 3410971 (51.32) \\
\hline Female & $2656(58.18)$ & $3236104(48.68)$ \\
\hline All & 4565 & 6647075 \\
\hline
\end{tabular}

The association of sex, age, and education with visual impairment (visual acuity worse than 6/18) was evaluated with logistic regression modelling using separate regression models for each of the independent variables at first. Then a multivariate logistic regression model with visual impairment as the outcome and sex, age, and education as the covariates was conducted. The odds ratios are shown in table 4 .

Principal causes of both best corrected and presenting visual impairment are shown in table 5 . While the principal causes of visual impairment according to the presenting vision were uncorrected refractive errors and cataract, according to the best corrected vision cataract, macular degeneration, and amblyopia were the most frequent primary causes of visual impairment in the study sample. In visually impaired people as a result of uncorrected refractive errors, $48.9 \%, 42.2 \%$, and $8.9 \%$ had hyperopia, myopia and astigmatism, respectively.

\section{DISCUSSION}

The TES is a population based study to investigate eye problems in Tehran population. This is the first report on the survey on visual impairment. The prevalence of blindness and low vision found in Tehran is rather lower than the values reported in other Middle East countries (table 6). ${ }^{373132}$ Comparisons among studies should be treated with caution, as the results are very sensitive to the definitions used and the population studied. The TES was executed on an urban population with much better access to health services like cataract surgery in comparison to the other parts of the country. Regarding the strong effect of the age distribution of the population on the overall estimate of visual impairment, it should be considered that Tehran has a young population. The characteristics of the study subjects, which included people from an urban area, were possibly comparable with inhabitants of most other large cities in Iran (nearly 30\% of the Iranian population) and the results of the study may show the visual status of this part of the population in the country.

Our study is not directly comparable with the two previous studies that have investigated this matter with different approaches. ${ }^{36}{ }^{37}$ Both of them are based on self reported visual function assessment.

In order to compare the results with other studies, we presented data using the WHO criteria for visual impairment, but the functional limitations caused by poor vision occurring at levels of visual acuity much better than the WHO criteria seem to be underestimated..$^{22}$ Therefore, we intend to report the results with other definitions for visual impairment.

Since visual impairment due to uncorrected or undercorrected refractive errors is missed with the best corrected

Table 2 Prevalence of visual impairment, low vision, and blindness by sex and age based on best corrected visual acuity*

\begin{tabular}{|c|c|c|c|c|c|}
\hline & Age (years) & No & Visual impairmentt & Low vision† & Blindness $†$ \\
\hline \multicolumn{6}{|l|}{ Men } \\
\hline & $1-19$ & 812 & 0.26 (0.06 to 1.06$)$ & 0.26 (0.06 to 1.06$)$ & 0 \\
\hline & $20-39$ & 492 & 0.91 (0.13 to 1.70$)$ & $0.73(0.27$ to 1.94$)$ & 0.18 (0.03 to 1.30$)$ \\
\hline & $40-59$ & 394 & 0.72 (0.23 to 2.26$)$ & $0.50(0.12$ to 2.06$)$ & 0.22 (0.03 to 1.54$)$ \\
\hline & $60+$ & 207 & 10.94 (6.86 to 15.01$)$ & 8.09 (4.71 to 11.47$)$ & $2.85(0.61$ to 5.09$)$ \\
\hline \multicolumn{6}{|l|}{ Women } \\
\hline & $1-19$ & 901 & 0 & 0 & 0 \\
\hline & $20-39$ & 923 & $0.32(0.10$ to 1.01$)$ & $0.32(0.10$ to 1.01$)$ & 0 \\
\hline & $40-59$ & 653 & $1.69(0.73$ to 2.65$)$ & $1.38(0.51$ to 2.26$)$ & 0.31 (0.08 to 1.24 ) \\
\hline & $60+$ & 178 & 14.35 (9.13 to 19.57$)$ & 11.59 (6.68 to 16.51$)$ & $2.75(0.39$ to 5.11$)$ \\
\hline \multicolumn{6}{|c|}{ Men and women } \\
\hline & $1-19$ & 1713 & $0.13(0.03$ to 0.54$)$ & $0.13(0.03$ to 0.54$)$ & 0 \\
\hline & $20-39$ & 1415 & $0.56(0.18$ to 0.94$)$ & $0.53(0.13$ to 0.93$)$ & $0.09(0.01$ to 0.70$)$ \\
\hline & $40-59$ & 1047 & 1.30 (0.64 to 1.96$)$ & $0.92(0.36$ to 1.48$)$ & 0.26 (0.08 to 0.82$)$ \\
\hline & $60+$ & 385 & $12.70(9.24$ to 16.16$)$ & $9.75(6.81$ to 12.68$)$ & $2.80(1.21$ to 4.39$)$ \\
\hline \multicolumn{6}{|l|}{ All ages } \\
\hline & Men & 1905 & $1.37(0.91$ to 1.83$)$ & 1.05 (0.67 to 1.44$)$ & 0.32 (0.10 to 0.53$)$ \\
\hline & Women & 2655 & $1.42(0.98$ to 1.86$)$ & $1.17(0.77$ to 1.57$)$ & 0.25 (0.07 to 0.43$)$ \\
\hline All participants & & $4560 \ddagger$ & $1.39(1.07$ to 1.71$)$ & 1.11 (0.84 to 1.39 ) & 0.28 (0.14 to 0.42$)$ \\
\hline
\end{tabular}

${ }^{*}$ Age and sex standardised to the 1996 Tehran population. †Percentage $(95 \% \mathrm{Cl})$.

†Data on visual acuity not available for five participants. 


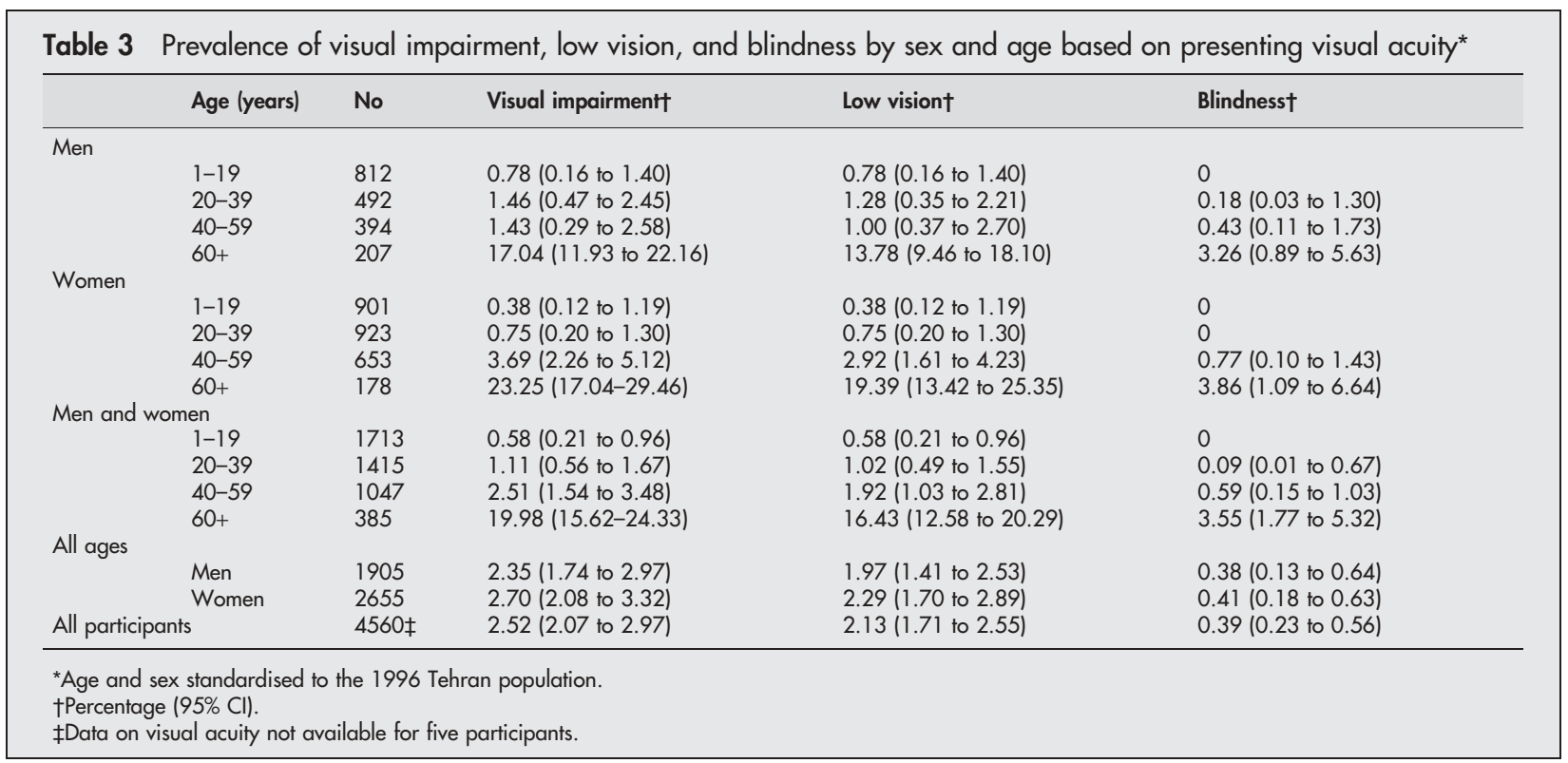

visual acuity definition, the results were presented based on presenting visual acuity as well. This definition would give the "real" magnitude of visual impairment in a population. ${ }^{42}$ Using the definition of visual impairment based on presenting visual acuity permitted the assessment of visual impairment due to refractive errors that were the most prevalent cause of visual impairment especially low vision.

Consistent with other population based studies, cataract was the leading cause of visual impairment based on best corrected visual acuity. ${ }^{5} 712131619222427$ 30-33 However, refractive errors were the principal cause of visual impairment using presenting visual acuity. Refractive errors are also one of the leading causes of visual impairment in different parts of the world..$^{402325}$ The burden of visual impairment due to refractive errors, in terms of visually impaired person years, is even more significant than the numbers indicate, since refractive error visual impairment mostly starts at a young age and probably causes significant economic and social burden to societies. ${ }^{42}$ On the basis of presenting vision, as much as $58.9 \%$ of visual impairment in the study population is due to cataract and refractive errors that are easily curable.

This study reports less glaucoma than some other surveys 243132 (table 6) for two reasons. Firstly, the study population is a very young one in which $69 \%$ are under 40 . Secondly, visual field examination was not performed.

The associations of visual impairment with sex, age and education were presented in table 4 . In correspondence with other studies, ${ }^{7} 2123253143$ visual impairment was associated with advancing age and lower education in this study. There was a 40 -fold increase in odds of being visually impaired between age groups of 60 years or older and 1-19 years (table 4). The association was consistent with both sexes and different levels of education; however, it was stronger for low vision in comparison with blindness and with the definition of visual impairment based on corrected vision. In contrast with some other studies, ${ }^{44}$ the prevalence of low vision and blindness was similar in both sexes before and after adjusting for age. Abou-Gareeb et al, ${ }^{44}$ through a meta-analysis, confirmed the association and interpreted it in many studies but it was shown that in some other studies the association was not present. The high prevalence of visual impairment in illiterate people after adjusting for age and sex was detected in this study, indicating a strong association between visual impairment and education. The observed associations show us target populations for interventional programmes against the problem in the community.

Table 4 Association of visual impairment with age, sex, and education

\begin{tabular}{|c|c|c|c|c|c|}
\hline & & \multicolumn{2}{|c|}{ Best corrected visual acuity } & \multicolumn{2}{|c|}{ Presenting visual acuity } \\
\hline & & $\mathrm{OR}^{*}$ & $95 \% \mathrm{Cl}+$ & $\mathrm{OR}^{*}$ & $95 \% \mathrm{Cl}+$ \\
\hline \multicolumn{6}{|l|}{ Age (years) } \\
\hline & $1-19$ & 1 & & 1 & \\
\hline & $20-39$ & 6.43 & 1.15 to 35.97 & 3.83 & 1.42 to 10.31 \\
\hline & $40-59$ & 6.53 & 1.39 to 30.68 & 5.28 & 2.11 to 13.22 \\
\hline & $60-99$ & 40.39 & 9.16 to 178.05 & 28.44 & 11.55 to 70.04 \\
\hline \multicolumn{6}{|l|}{ Sex } \\
\hline & Female & 1 & & 1 & \\
\hline & Male & 1.09 & 0.67 to 1.77 & 1.22 & 0.84 to 1.76 \\
\hline \multicolumn{6}{|l|}{ Education $\ddagger$} \\
\hline & College & 1 & & 1 & \\
\hline & Secondary school & 1.32 & 0.38 to 4.57 & 1.85 & 0.70 to 4.84 \\
\hline & Primary school & 5.31 & 1.39 to 20.33 & 5.56 & 1.97 to 15.68 \\
\hline & Illiterate & 12.48 & 3.66 to 42.50 & 13.07 & 5.09 to 33.56 \\
\hline
\end{tabular}

*Adjusted odds ratio (multiple logistic regression).

† $95 \%$ confidence interval.

†Education: illiterate $=$ no formal schooling, primary $=1-5$ years of schooling, secondary $=7-12$ years of

schooling, and college = more than 12 years of schooling. 
Table 5 Causes of visual impairment based on presenting and best corrected visual acuity*

\begin{tabular}{lll}
\hline Causes & Best corrected visual acuity & Presenting visual acuity \\
\hline Refractive errors & - & $45(33.6)$ \\
Cataract & $27(36.0)$ & $34(25.4)$ \\
Amblyopia & $8(10.7)$ & $11(8.2)$ \\
Macular degeneration & $15(20.0)$ & $17(12.7)$ \\
Corneal opacity & $5(6.7)$ & $5(3.7)$ \\
Vascular retinopathy & $3(4.0)$ & $3(2.2)$ \\
Glaucoma & $2(2.7)$ & $3(2.2)$ \\
Optic atrophy & $2(2.7)$ & $3(2.2)$ \\
Keratoconus & $2(2.7)$ & $3(2.2)$ \\
Others† & $11(14.7)$ & $10(7.5)$ \\
Total & 75 & 134 \\
\hline *Number (\%). & \\
†Trauma, absent globe, diabetic retinopathy, optic nerve hypoplasia.
\end{tabular}

Table 6 Prevalence of blindness and its causes reported from population based studies in selected countries

\begin{tabular}{|c|c|c|c|c|c|}
\hline Country & $\begin{array}{l}\text { Sample } \\
\text { size }\end{array}$ & $\begin{array}{l}\text { Age } \\
\text { (years) }\end{array}$ & Definition & Prevalence (\%) & Main causes (\%) \\
\hline Lebanon $^{7}$ & 10148 & $3 \leqslant$ & $<3 / 60$ & 0.6 & $\begin{array}{l}\text { Cataract (41.3), refractive errors (12.6), corneal opacities (7.5), optic } \\
\text { atrophy (7.5), trauma (5.0), macular degeneration (3.8), diabetic } \\
\text { retinopathy (2.5), glaucoma (2.5) }\end{array}$ \\
\hline $\mathrm{Nepal}^{13}$ & 4602 & $45 \leqslant$ & $<6 / 60$ & 5.3 & Cataract $(78)$, trachoma (NA), refractive errors (NA), glaucoma (NA) \\
\hline China $^{16}$ & 5342 & $50 \leqslant$ & $<6 / 60$ & 4.37 & Cataract (61.5), refractive errors (10) \\
\hline Hong Kong ${ }^{23}$ & 3441 & $60 \leqslant$ & $<3 / 60$ & 1.8 & Cataract (51.7), macular degeneration (27.1), glaucoma (7.1) \\
\hline Equatorial Guinea $^{24}$ & 3218 & All & $<3 / 60$ & 3.2 & $\begin{array}{l}\text { Cataracts (61.3); macular affection (25.3), optic atrophy (16), glaucoma } \\
(13.3 \%)\end{array}$ \\
\hline India ${ }^{27}$ & 5411 & $50 \leqslant$ & $<3 / 60$ & 4.1 & Cataract (64.4), refractive errors (23.3), ARMD (2.9), glaucoma (2.3) \\
\hline Malaysia $^{30}$ & 18027 & All & $<3 / 60$ & 0.29 & $\begin{array}{l}\text { Cataract (39.1), retinal diseases (24.5), refractive errors (4.1), corneal } \\
\text { diseases (3.4), glaucoma (1.8) }\end{array}$ \\
\hline $\mathrm{Oman}^{31}$ & 11417 & All & $<3 / 60$ & 1.1 & Cataract (30.5), trachomatous corneal opacities (23.7), glaucoma (1 1.5) \\
\hline Turkmenistan $^{32}$ & 6011 & $50 \leqslant$ & $<3 / 60$ & 1.26 & Cataract (54), glaucoma (25) \\
\hline
\end{tabular}

\section{Limitations}

There are some limitations to our study that must be acknowledged. Firstly, although the total sample size was appropriate to estimate the prevalence in the whole population, the desired level of precision was not always obtained for some of the estimates in the age and sex groups. However, considering the lack of previous data on the population we have rough estimations in age or sex specific prevalences, which can guide interventional control programmes or further studies in the country.

Secondly, despite the acceptable response rate $(70.3 \%)$, the prevalence of visual impairment may have been overestimated assuming that those not examined may have been less likely to be suffering from impaired vision. It is generally accepted that visually impaired people are over-represented in such studies, but some authors report contradictory results on this matter. ${ }^{24}$ On the other hand, since prevalence estimates were based only on visual acuity measurements, some visual impairment associated with visual field defects could have been missed, resulting in a potential underestimation.

Thirdly, our survey was carried out on a population based sample of Tehran population with special socioeconomic characteristics so that we cannot extrapolate the results to the whole population of the country. More research in other regions including rural areas is indicated. However, we believe our data, which are the first population based data describing visual impairment in the country provide valuable insight into the magnitude of the problem in the community. This study highlights the need to target intervention programmes for prevention of visual impairment to elderly people and those with little or no education as the high risk groups.

\section{ACKNOWLEDGEMENTS}

This project is funded in part by the Noor Vision Correction Centre, and a grant from the Iranian National Research Centre for Medical Sciences. The selection of clusters was based on block enumeration of the national census of 1996 by the Iranian Statistics Centre. The authors also acknowledge the assistance of Dr Shiva Mehravaran in the preparation of this manuscript.

\section{Authors' affiliations}

A Fotouhi, K Mohammad, Epidemiology and Biostatistics Department, School of Public Health, Tehran University of Medical Sciences, Tehran, Iran

H Hashemi, Farabi Eye Hospital, School of Medicine, Tehran University of Medical Sciences, Tehran, Iran

H Hashemi, K H Jalali, Noor Vision Correction Center, Tehran, Iran

Competing interests: None declared.

\section{REFERENCES}

1 Thylefors B. A mission for vision. Lancet 1999;354(Suppl):SIV44.

2 Thylefors B, Negrel AD, Pararajasegaram R, et al. Global data on blindness. Bull World Health Organ 1995;73:115-21.

3 Tabbara KF. Blindness in the eastern Mediterranean countries. Br J Ophthalmol 2001;85:771-7.

4 Klein R, Klein BEK, Linton KLP, et al. The Beaver Dam Eye Study: visual acuity. Ophthalmology 1991;98:1310-15.

5 Attebo K, Mitchell P, Smith W. Visual acuity and the causes of visual loss in Australia. The Blue Mountains Eye Study. Ophthalmology 1996; 103:357-64.

6 Rahmani B, Tielsch JM, Katz J, et al. The cause-specific prevalence of visual impairment in an urban population. The Baltimore Eye Survey. Ophthalmology 1996;103:1721-6.

7 Mansour AM, Kassak K, Chaya M, et al. National survey of blindness and low vision in Lebanon. Br J Ophthalmol 1997;81:905-6.

8 Rubin GS, West SK, Munoz B, et al. A comprehensive assessment of visual impairment in a population of older Americans. The SEE Study. Salisbury Eye Evaluation Project. Invest Ophthalmol Vis Sci 1997;38:557-68. 
9 Taylor HR, Livingston PM, Stanislavsky YL, et al. Visual impairment in Australia: distance visual acuity, near vision, and visual field findings of the Melbourne Visual Impairment Project. Am J Ophthalmol 1997;123:328-37.

10 Klaver CCW, Wolfs RCW, Vingerling JR, et al. Age- specific prevalence and causes of blindness and visual impairment in an older population: The Rotterdam Study. Arch Ophthalmol 1998;116:653-8.

11 Lee DJ, Gomez-Marin O, Lam BL. Prevalence of uncorrected binocular distance visual acuity in Hispanic and non-Hispanic adults. Ophthalmology 1998; 105:552-60.

12 Zhao J, Jia L, Sui R, et al. Prevalence of blindness and cataract surgery in Shunyi county, China. Am J Ophthalmol 1998;126:506-14.

13 Pokharel GP, Regmi G, Shrestha SK, et al. Prevalence of blindness and cataract surgery in Nepal. Br J Ophthalmol 1998;82:600-5.

14 Munier A, Gunning T, Kenny D, et al. Causes of blindness in the adult population of the Republic of Ireland. Br J Ophthalmol 1998;82:630-3.

15 See JLS, Wong TY, Yeo KT. Trends in the pattern of blindness and major ocular diseases in Singapore and Asia. Ann Acad Med Singapore 1998;27:540-6.

$16 \mathrm{He} \mathrm{M}, \mathrm{Xu}_{\mathrm{U}} \mathrm{J}$, Li S, et al. A survey of blindness and cataract surgery in Doumen County, China. Ophthalmology 1999;106:1602-8.

17 Weih LM, VanNewkirk MR, McCarty CA, et al. Age-specific causes of bilateral visual impairment. Arch Ophthalmol 2000;118:264-9.

18 Van der Pols JC, Bates CJ, McGraw PV, et al. Visual acuity measurements in a national sample of British elderly people. Br J Ophthalmol 2000;84:165-70.

19 Murthy GVS, Gupta S, Ellwein LB, et al. A population-based eye survey of older adults in a rural district of Rajasthan. Ophthalmology 2001; 108:679-85.

20 VanNewkirk MR, Weih LA, McCarty CA, et al. Cause-specific prevalence of bilateral visual impairment in Victoria, Australia. Ophthalmology 2001;108:960-7.

21 Hyman L, Wu SY, Connell AMS, et al. Prevalence and causes of visual impairment in the Barbados Eye Study. Ophthalmology 2001;108:1751-6.

22 Buch H, Vinding T, Nielsen NV. Prevalence and causes of visual impairment according to World Health Organization and United States criteria in an aged, urban Scandinavian population, The Copenhagen City Eye Study. Ophthalmology 2001;108:2347-57.

23 Michon JJ, Lau J, Chan WS, et al. Prevalence of visual impairment, blindness, and cataract surgery in the Hong Kong elderly. Br J Ophthalmol 2002;86:133-9.

24 Moser CL, Martin-Baranera M, Vega F. Survey of blindness and visual impairment in Bioko, Equatorial Guinea. Br J Ophthalmol 2002;86:257-60.

25 Dandona $\mathbf{R}$, Dandona $L$, Srinivas $M$, et al. Moderate visual impairment in India: the Andhra Pradesh Eye Disease Study. Br J Ophthalmol 2002;86:373-7.

26 Munoz B, West SK. Blindness and visual impairment in the Americas and the Caribbean. Br J Ophthalmol 2002;86:498-504.
27 Nirmalan PK, Thulasirai RD, Maneksha V et al. A population based eye survey of older adults in Tirunelveli district of south India: blindness, catarac surgery, and visual outcomes. Br J Ophthalmol 2002;86:505-12.

28 Kocur I, Resnikoff S. Visual impairment and blindness in Europe and their prevention. Br J Ophthalmol 2002:86:716-22.

29 Evans JR, Fletcher AE, Wormald RPL, et al. Prevalence of visual impairment in people aged 75 years and older in Britain: results from the MRC trial of assessment and management of older people in the community. Br J Ophthalmol 2002;86:795-800.

30 Zainal M, Ismail SM, Ropilah AR, et al. Prevalence of blindness and low vision in Malaysian population: results from the National Eye Survey 1996. Br J Ophthalmol 2002;86:951-6.

31 Khandekar R, Mohammed AJ, Negrel AD, et al. The prevalence and causes of blindness in the Sultanate of Oman: the Oman Eye Study (OES). Br J Ophthalmol 2002:86:957-62.

32 Amansakhatov S, Volokhovskaya ZP, Afanasyeva AN, et al. Cataract blindness in Turkmenistan: results of a national survey. $\mathrm{Br} J$ Ophthalmol 2002;86:1207-10

33 Rodriguez J, Sanchez R, Munoz B, et al. Causes of blindness and visual impairment in a population- based sample of US Hispanics. Ophthalmology 2002; 109:737-43.

34 Bourne RRA, Dineen B, Ali SM, et al. The national blindness and low vision prevalence of Bangladesh: research design, eye examination methodology and results of pilot study. Ophthalmic Epidemiol 2002;9:119-32.

35 Thulasiraj RD, Rahmathulla R, Saraswati A, et al. The Sivaganga Eye Survey: I. Blindness and cataract surgery. Ophthalmic Epidemiol 2002;9:299-312.

36 Mohammad K, Joghatai MT, Syiadati S, et al. A national survey of visual disturbances In Iran. J Medical Council of IRI 2001;19:203-9 (in Persian).

37 Noorbala AA, Mohammad K. National health survey of Iran. Iran: The National Research Center for Medical Sciences, 2001 (in Persian).

38 Hashemi H, Fotouhi A, Mohammad K. Tehran Eye Study: research design and eye examination protocol. BMC Ophthalmol 2003;3:8

39 World Health Organization. In: International Statistical Classification of Diseases and Related Health Problems, 10th revised edition. Geneva: WHO, 1992.

40 Bennett S, Woods T, Liyanage WM, et al. A simplified method for cluster sample surveys of health in developing countries. World Health Statistics Quarterly 1991;44:98-106.

41 Iranian Statistics Center. The report of the 1996 population census. (amar.sci.or.ir, accessed 10 March 2003.)

42 Dandona R, Dandona L. Refractive error blindness. Bull World Health Organ 2001;79:237-43.

43 Livingston PM, McCarty CA, Taylor HR. Visual impairment and socioeconomic factors. Br J Ophthalmol 1997;81:574-7.

44 Abou-Gareeb, Lewallen S, Bassett K, et al. Gender and blindness: a metaanalysis of population-based prevalence surveys. Ophthalmic Epidemiol $2001 ; 8: 39-56$ 